\title{
Del trabajo al paro y del paro al subsidio: Cambios en las culturas del trabajo de los jornaleros andaluces
}

\author{
PABLO PALENZUELA \\ Grupo de Investigación GEISA \\ Departamento de Antropología Social \\ Universidad de Sevilla
}

\section{INTRODUCCIÓN}

Este artículo, cuyo marco disciplinar es la antropología del trabajo, tiene como hilo conductor el concepto de culturas del trabajo y como referente empírico la transformación de los procesos de trabajo en la agricultura andaluza a partir de la mecanización intensiva de los cultivos en las tres últimas décadas del siglo Xx. Este factor de carácter estructural en el proceso productivo agrícola, coadyuvado con la intervención del Estado institucionalizando las medidas asistenciales en favor de los trabajadores eventuales agrarios, ha dado lugar al alejamiento del jornalero del trabajo en la tierra y a su incorporación al sector de la población asistida. La reducción drástica de las oportunidades de ejercer el oficio de jornalero para muchos jóvenes del medio rural que alcanzaron su edad adulta en 1984, año de entrada en vigencia del Subsidio de Desempleo Agrario, hace desaparecer prácticamente las bases materiales sobre las que se construyó y se reprodujo una cultura del trabajo jornalera impugnadora, dignificadora y solidaria. La acción colectiva de resistencia a la mecanización y en defensa del trabajo en la tierra durante los años setenta va a coincidir con las movilizaciones por la continuidad y la extensión del Empleo Comunitario y esa simultaneidad de reivindicaciones expresadas colectivamente dejará paso progresivamente a la preocupación individual por «arreglar los papeles del paro" y a la práctica desmovilización de los jornaleros.

Las ideas del "cumplir", el "reparto" y la "unión" (cf. Martínez Alier 1968), que fueron los tres pilares que definieron ideacionalmente la cultura jornalera del trabajo, así como las condiciones particulares de inserción de los jornaleros en los procesos de trabajo agrícolas, que constituyeron la base material de dichas culturas del trabajo, desaparecen paulatinamente de la orientación cognitiva y de la experiencia cotidiana del jornalero andaluz para llevarlo a lo que Ortí (1984) llamó ala agonía final de la conciencia jornaleran. 
A partir de la presentación del concepto "culturas del trabajo" y de su potencialidad epistemológica para el análisis de las prácticas sociales vamos a recorrer el proceso irreversible que transforma un colectivo, cuya identidad social es resultado, junto a otros factores, de su cultura del trabajo, en una masa amorfa de asistidos sociales para los cuales la etiqueta de "jornalero" tiene hoy día una significación más administrativa que socio-profesional.

\section{Clase social, Culturas Del trabajo E IDENTIDADES SOCIALES}

El resultado general al que llegué y que, una vez obtenido, me sirvió de guía para mis estudios, puede formularse brevemente de este modo: en la producción social de su existencia, los hombres entran en relaciones determinadas, necesarias, independientes de su voluntad; estas relaciones de producción corresponden a un grado determinado de desarrollo de sus fuerzas productivas materiales. El conjunto de esas relaciones de producción constituye la estructura económica de la sociedad, la base real, sobre la que se eleva una superestructura jurídica y política y a la que corresponden formas sociales determinadas de conciencia. El modo de producción de la vida material condiciona el proceso de la vida social, política e intelectual, en general. No es la conciencia de los hombres la que determina la realidad; por el contrario, la realidad social es la que determina su conciencia (Marx 1970).

La anterior formulación sintética del materialismo histórico ha servido de guía metodológica para una buena parte de la producción científicosocial desde su publicación en 1859 , aunque por culpa de la exégesis dogmática realizada por Stalin en 1938 e impuesta al pensamiento marxista hasta las últimas décadas del siglo $\mathrm{xx}$, su potencialidad epistemológica se vio limitada, dando lugar a interpretaciones mecanicistas y escasamente dialécticas de la realidad social. Como afirma Habermans (1992: 144): Durante mucho tiempo ha venido dominando una versión económica de este teoreman.

Sin embargo, el concepto de relaciones sociales de producción, definido como conjunto de relaciones que los individuos establecen entre sí y con respecto a los medios de producción en los procesos productivos, se ha mantenido como piedra angular en el análisis de la producción y de la reproducción social, realizado desde el paradigma materialista. Esas relaciones son sociales ya que la producción en sí misma está determinada por necesidades social e históricamente definidas y el trabajo humano no puede ser otra cosa que trabajo social. Además de ser un mecanismo de socialización del trabajo, las relaciones sociales de producción determinan la posición objetiva de los individuos, tanto en la producción mis- 
ma como en la estructura de clases y constituyen la base desde la que se generan las distintas formas (alienadas o impugnadoras) de conciencia social.

Una formación económico-social supone la coexistencia de varios modos de producción y, en consecuencia, de otros tantos modelos de relaciones sociales de producción, cuya expresión jurídica son las distintas formas de propiedad de los medios de producción y de apropiación de la fuerza de trabajo. De entre todos ellos, un concreto modelo de relaciones sociales de producción termina subsumiendo a los demás para otorgar carta de naturaleza al modo de producción dominante y definir tanto los mecanismos de funcionamiento de la base material como las construcciones ideacionales de la forma social. Ambas instancias (lo material y lo ideal, como las denomina M. Godelier, 1990), cuyo nivel de causalidad en la producción de lo social no puede determinarse apriorísticamente, son perceptibles en su imbricación dialéctica en los procesos de trabajo, es decir, allí donde toman cuerpo las relaciones sociales de producción.

Por ello, los procesos de trabajo, especialmente aquellos que se aplican a la producción directa de mercancías (trabajo directamente productivo, según Marx), constituyen el primer escalón de un proceso metodológico como el que propone Emmanuel Terray (1969: 100) para identificar la naturaleza de una formación social:

1. Hacer el inventario de los procesos de trabajo, sin olvidar que se ejecutan dentro de unas determinadas relaciones sociales de producción.

2. Localizar los diversos tipos de procesos de producción en cada formación económico-social, teniendo en cuenta que el conjunto de los procesos de trabajo, y las relaciones sociales de producción en las cuales el trabajo se realiza, constituyen un proceso de producción.

3. Analizar las unidades de producción como marco concreto donde ésta se efectúa, teniendo presente que sus dimensiones y estructura vienen determinadas a la vez por las fuerzas productivas y las relaciones de producción.

4. Finalmente, estudiar la representación de las relaciones de producción en el nivel de la superestructura jurídico-político-ideológica, sin olvidar que en determinadas condiciones, instancias tanto políticas como religiosas, incluso los sistemas de parentesco en las sociedades segmentarias, por ejemplo, pueden intervenir en la constitución de verdaderas relaciones de producción.

Junto al concepto de relaciones sociales de producción, y como directa derivación de él, aparece el de clase social que se convertirá en la 
herramienta epistemológica clave de la perspectiva marxista en el análisis de las sociedades. Según la clásica definición leninista:

Las clases son vastos grupos de hombres que se distinguen por el lugar que ocupan dentro de un sistema históricamente determinado de producción social, por su relación - la mayoría de las veces fijada y formulada por leyes- con los medios de producción, por su papel en la organización del trabajo y, por lo tanto, por las dimensiones de su participación en la riqueza social de que disponen y el modo de adquirirla (Lenin 1919).

Esta definición, que rezuma un fuerte contenido economicista, será completada más tarde por autores como Poulantzas (1972, tomo 1: 62 y 65) al entender que la clase no es sólo la consecuencia de una determinada estructura económica, sino el producto de la acción combinada de diferentes estructuras - económicas, políticas, jurídicas, ideológicas- cuya combinación constituye un modo de producción y una formación social determinados. En otro de sus textos N. Poulantzas (1974: 16) reelabora y completa la definición leninista de clase social al afirmar:

Las clases sociales son conjuntos de agentes sociales determinados principalmente, pero no exclusivamente, por su lugar en el proceso de producción, es decir, en la esfera económica. Sin embargo, no se debe concluir que, debido al lugar principal de la esfera económica, ésta sola bastaría para la determinación de las clases sociales.

A dicha dimensión económica, que está vinculada directamente con las relaciones de producción, se incorporan las dimensiones políticas, jurídicas e ideológicas, presentes en las relaciones y en las prácticas sociales, para dotar al concepto de clase social de una naturaleza ontológica.

Finalmente, el concepto adquiere un contenido dinámico al entender que la clase social está estructuralmente determinada por las prácticas de clase, es decir, por la lucha de clases que confronta intereses antagónicos en el seno de las relaciones sociales de producción. Esa determinación estructural es distinta de la posición coyuntural que una clase social o una fracción de ella puede adoptar en un momento determinado. Por ejemplo, la llamada aristocracia obrera en determinadas ocasiones puede adoptar posiciones burguesas sin que ello suponga que forma parte de la burguesía o que sectores de la pequeña burguesía, como el campesinado, puedan compartir las posiciones del proletariado sin que ello les integre en dicha clase social.

Esta cuestión nos lleva directamente a la diferenciación entre clase en sí (determinación objetiva de clase únicamente por el proceso de producción) y clase para sí (dotada de una consciencia de clase propia y de 
una organización política autónoma), requisitos que G. Lukacs (1985) entiende necesarios para que una clase se convierta en una fuerza social. La consciencia de clase es, según Lukacs (ibid. 115):

la reacción racionalmente adecuada que se atribuye de este modo a una determinada situación típica en el proceso de la producción. Esta consciencia no es, pues, ni la suma ni la media de lo que los individuos singulares que componen la clase piensan, sienten, etc..

Relaciones sociales de producción, clase social y consciencia de clase han funcionado pues como conceptos clave en el análisis de las estructuras sociales y también en la comprensión de las prácticas sociales (especialmente de las económicas y políticas), así como de las orientaciones cognitivas de los individuos y de los grupos sociales. Sin embargo, su eficacia epistemológica, demostrada en las fases históricas de un capitalismo emergente de base nacional cuya estructura social pivotaba sobre la polarización burguesía/proletariado, se ha ido reduciendo a medida que avanzaba el proceso de complejización social y de fraccionamiento de la estructura social del capitalismo.

En un anterior trabajo (Palenzuela 1995: 12) avanzamos la idea de la necesidad de un análisis de mayor finezza para la validación de la teoría marxista sobre las clases sociales en el capitalismo contemporáneo:

La teoría marxista sobre las clases sociales y el propio concepto de clase social siguen siendo, en nuestra opinión, referencias teóricas y conceptuales válidas, pero insuficientemente explicativas en el marco del capital monopolista.

Porque, hoy día un concepto tan cerrado y ontológico como el de clase social, incluso en su acepción más omnicomprensiva como locus de las dimensiones económicas, políticas e ideológicas, nos servirá, como mucho, para desbrozar el terreno de la determinación de las estructuras sociales, pero difícilmente nos ilustrará sobre el sentido de las prácticas sociales. Tampoco el concepto de consciencia de clase, tal como lo define Lukacs, parece tener mucha utilidad hoy para entender la diversidad de cosmovisiones de los individuos que objetivamente comparten una misma posición en las relaciones sociales de producción.

En definitiva, la identidad social, que orienta las prácticas de los grupos sociales y condiciona su particular interpretación de la realidad, no puede ser subsumida por la identidad de clase ni por la consciencia de clase, porque:

Contrariamente a lo que muchos, explícita o implícitamente, entienden, en el mundo actual —en nuestra "aldea global — no es el sistema de clases el único 
estructurante a partir del cual se generan todas las demás divisiones, contradicciones y conflictos sociales. Y tampoco, desde nuestro análisis, la lista de principios generadores de identidades básicas es ilimitada, ni son equivalentes en su importancia. Por mi parte considero que existen tres principios fundamentales que actúan sobre cada individuo tendiendo a generar en él, cada uno de ellos autónomamente, una identidad globalizadora. Mi identidad como persona posee estos tres componentes básicos, estructurales: mi identidad étnica, mi identidad de género y mi identidad de clase y profesional (Moreno 1991: 603).

Esta cita del antropólogo andaluz I. Moreno, en la que se sintetiza el marco teórico elaborado en el seno del Grupo para el Estudio de las Identidades Socioculturales en Andalucía (GEISA), nos propone, desde la constatación de la multiplicidad de factores que intervienen en la conformación de la identidad social, un recorrido metodológico que empiece por una ordenación de la causalidad de dichos factores, diferenciando los estructurantes (etnicidad, género y clase social, de cuya imbricación resulta la matriz identitaria) de los demás (grupos de edad, adscripción política, creencias religiosas, etc.) que también intervienen, aunque de forma no estructural, en la identidad social.

De los tres principios estructurantes se derivan tres identidades básicas, no irreductibles entre sí, que constituyen tres universos culturales: la cultura étnica, la cultura de género y las culturas del trabajo.

A los efectos de este trabajo, y sin olvidar la imbricación y la irreductibilidad de los tres principios estructurantes de la identidad social, vamos a centrarnos en el concepto de culturas del trabajo que ya definimos en otro artículo como:

Conjunto de conocimientos teórico-prácticos, comportamientos, percepciones, actitudes y valores que los individuos adquieren y construyen a partir de su inserción en los procesos de trabajo y/o de la interiorización de la ideología sobre el trabajo, todo lo cual modela su interacción social más allá de su práctica laboral concreta y orienta su específica cosmovisión como miembros de un colectivo determinado (Palenzuela 1995: 13).

Las culturas del trabajo, que están irremediablemente generizadas y etnicizadas, se generan en los procesos de trabajo, desde una determinada posición en las relaciones de producción, y constituyen un constructo social dinámico resultante de la articulación dialéctica entre su base material (los procesos de trabajo) y su configuración ideacional (la ideología del trabajo socialmente establecida y su reinterpretación a partir de las experiencias laborales). La transformación de alguna de estas instancias y de su imbricación dará lugar a unas nuevas culturas del trabajo y, en consecuencia, a un proceso de resignificación de las identidades sociales del colectivo. 
Ese es el trayecto que en las últimas décadas han recorrido los jornaleros andaluces y sus culturas del trabajo con el resultado de una pérdida de identidad social, al desaparecer las bases materiales sobre las que se generaron sus culturas del trabajo.

\section{LOS CONTENIDOS IDEACIONALES Y MATERIALES DE LAS CULTURAS DEL TRABAJO JORNALERAS}

Retomando la propuesta metodológica de E. Terray citada más arriba y adaptándola a nuestros objetivos, debemos empezar por acercarnos a los procesos de trabajo en los que se inserta la mano de obra jornalera como primer peldaño para identificar las culturas del trabajo construidas y reproducidas en el pasado por este colectivo.

La fuerza de trabajo jornalera, como mano de obra simple, no cualificada, eventual y excedentaria se incorpora a los procesos de trabajo agrícolas de forma intermitente según el ritmo y las necesidades de los cultivos. Su marco laboral preeminente, aunque no el único, es la gran propiedad latifundista en la que realiza tareas sencillas y repetitivas como las de plantación, selección de brotes, escarda de malas hierbas y recolección de frutos. Aunque la vinculación contractual, siempre bajo forma verbal y temporal, relaciona a cada jornalero con el propietario, la organización del trabajo agrícola induce a la realización de tareas de forma colectiva (en cuadrilla o como grupo familiar). La cuadrilla es la unidad básica de agrupación de la mano de obra jornalera. Todos sus componentes, cuyo número puede variar desde tres o cuatro hasta treinta o cuarenta, realizan una misma tarea agrícola bajo la supervisión directa del capataz o encargado. Su composición se adapta a las exigencias del cultivo y a las conveniencias del empleador, pero suele mantener un núcleo fijo de componentes, entre los cuales está el manijero que realiza funciones de representación del grupo y de intermediación con el patrón o sus representantes. Normalmente cada cuadrilla es identificada por el nombre o el alias de su manijero y se aplican a todos sus miembros por extensión las cualidades de honradez, fiabilidad o rendimiento de su representante. Por su parte, el grupo familiar (familia nuclear o extensa) se incorpora al trabajo agrícola en momentos en que la demanda de trabajo es alta y concentrada en pocas fechas. En esta modalidad es el cabeza de familia quien ejerce las funciones de intermediación con la propiedad, cuyo resultado vincula a todos los miembros del grupo familiar.

El trabajo puede ser hecho a jornal, es decir, retribuido con un salario diario por un volumen de trabajo estimado a realizar en un horario 
preestablecido. La "peoná" es un término habitual en el léxico jornalero que designa tanto el montante de la retribución diaria ("cobrar la peonán) como el tiempo de trabajo a cumplir en cada jornada ("echar la peonán). La otra modalidad de organización y retribución del trabajo jornalero es el destajo, es decir, la percepción de una cantidad de dinero por cada unidad de trabajo realizada. La unidad de cómputo de la retribución a destajo varía según el cultivo (puede ser el kilo de fruto recogido como en la vendimia o en el algodón, o el camión cargado como en la saca de la remolacha).

Las dos formas de organización del trabajo (cuadrilla y grupo familiar) y las dos modalidades de retribución (jornal y destajo) pueden combinarse en el siguiente esquema que hemos tomado de F. Talego (1996: 20): 1) Cuadrilla a jornal. 2) Cuadrilla a destajo. 3) Grupo familiar a jornal. 4) Grupo familiar a destajo. Sin embargo, es importante subrayar que este marco de posibilidades no supone una opcionalidad a disposición del jornalero. La aplicación de una u otra modalidad de trabajo y de retribución es resultado de la decisión unilateral del patrón, según su propio interés y las exigencias de cada cultivo. El destajo se aplicará a aquellas tareas cuya ejecución no necesite un alto grado de calidad o precisión y deban realizarse en cortos periodos de tiempo. Pero, este esquema jerárquico y autoritario de relaciones laborales tiene su respuesta por parte de los jornaleros. Su traducción en términos de rendimiento y de calidad del trabajo realizado en una jornada no suele coincidir con las expectativas del patrón o con las exigencias del capataz. Se trata de una doble interpretación del "cumplir» en el trabajo que da lugar a conflictos más o menos explícitos en los tajos y que, en última instancia, se resuelve de forma totalitaria por la aplicación de los esquemas disciplinarios en manos de la patronal, incluido el poder discrecional de suspender la contratación verbal, salvo si "la unión" de los trabajadores es suficientemente fuerte para limitar el poder, en principio, cuasi omnímodo del patrón.

Al tratarse de procesos de trabajo simples, susceptibles de ser ejecutados por una mano de obra casi siempre excedentaria que no necesita un prolongado periodo de aprendizaje, y estar integrados en un modelo de relaciones laborales de naturaleza autoritaria y discrecional, su nivel de retribución real ha estado casi siempre por debajo de las cuantías mínimas establecidas en las Ordenanzas Laborales y en los Convenios Colectivos del Campo. De tal modo que la intermitencia en la contratación, junto a la baja retribución del trabajo, ha condenado a las familias jornaleras a unos niveles de renta cercanos a la estricta subsistencia. Los largos periodos de ausencia de ingresos salariales han forzado a los jornaleros a desarrollar estrategias de complementariedad de rentas, bien 
mediante la movilidad hacia otros mercados de trabajo agrícolas (el circuito de la eventualidad) o la salarización coyuntural en otros sectores (hostelería, construcción, etc.) o bien mediante el recurso a actividades de renta marginal (Palenzuela 1996) para "buscarse la vida" (caza furtiva, recolección de espárragos, marisqueo, elaboración de carbón vegetal, etc.).

En nuestro trabajo de campo realizado en 1984 en Lebrija, al analizar la composición de las rentas familiares de una serie de grupos domésticos jornaleros con presencia de algún especialista en actividades de renta marginal, pudimos constatar la diferente significación que para ellos tenía el trabajo/trabajo del "buscarse la vida. El verdadero trabajo era aquel que se realizaba bajo formas salariales, en condiciones de duración y retribución preestablecidas, ejecutado de forma colectiva y sometido a la jerarquía de mando. Lo otro, aunque tuviera en ciertas ocasiones favorables un mayor rendimiento económico, era una actividad denigrante («bandolerismon), sólo aceptada por razones de estricta necesidad y rechazada socialmente cuando sus rendimientos económicos no se destinaban al sustento del grupo familiar.

La precariedad de las rentas familiares, con largos periodos de carestía de ingresos, y el modelo autoritario de relaciones laborales basado en la decisión discrecional del empleador, apoyado en un enorme ejército de reserva de mano de obra y en esquemas disciplinarios que, en tiempos de la dictadura, se acercaban a los del campo de concentración (Sumpsi y Naredo 1984), han dado lugar a diversas formas de solidaridad intragrupal en los procesos de trabajo y en el medio social jornalero. Algunas de esas formas de ayuda mutua, como el "tornapeón", que supone la realización de una peoná en lugar de un compañero impedido con la obligación diferida de devolución, o el "pañuelo", que representa la colecta de dinero entre la cuadrilla para ayudar a la familia de un compañero enfermo, fueron analizadas a la luz de la Teoría del Don de Marcel Mauss en un anterior trabajo nuestro (Palenzuela y Cruces 1995), y otras, como la compra "a fiao" o el préstamo familiar, han permitido a muchas familias jornaleras subsistir en los periodos de desempleo.

En definitiva, la base material de las culturas del trabajo jornaleras está sustentada en procesos de trabajo de contenido poco especializado, de carácter estacional, con una enorme dispersión en el espacio y continuos cambios en la relación patrón/trabajador y en la propia composición del colectivo que aporta la fuerza de trabajo. Además, el modelo de relaciones laborales que atraviesa esos procesos de trabajo está basado en la discrecionalidad y el autoritarismo de la patronal que busca el mayor nivel de consentimiento por parte de la fuerza de trabajo y mantiene las retribuciones en niveles cercanos a la subsistencia. 
En cuanto a su contenido ideático, las culturas del trabajo de los jornaleros reflejan, de alguna forma, la escala de valores construida desde la ideología de trabajo dominante que asigna una escasa valoración social a la labor manual realizada por los jornaleros. Esta infravaloración es internalizada por el colectivo de trabajadores agrícolas que, a pesar de las connotaciones románticas y combativas que encierra el vocablo ijornalero", prefieren utilizar, tal como ha demostrado F. Talego (1997), la expresión "obrero del campo" para autoidentificarse como grupo profesional o sindical más cercano, al menos en la etiqueta, a los trabajadores urbanos. No es casualidad que actualmente no exista en Andalucía ningún sindicato que utilice la apelación "jornalero", aunque la primera plataforma sindical clandestina después de la Guerra Civil adoptó en 1966 el nombre de Comisiones Jornaleras. Hoy tienen presencia real en el campo andaluz la Federación de Trabajadores de la Tierra de la UGT, las Comisiones del Campo en CC.OO y el SOC (Sindicato de Obreros del Campo).

En el esquema "cultura letrada" vs. "cultura iletrada" (ver Iturra 1993: 131-152) los jornaleros son integrados claramente en el segundo polo del binomio y todo su saber hacer y el conocimiento del medio adquirido por el trabajo apenas encuentran valoración fuera del propio sector jornalero. Su cultura, basada en la experiencia y transmitida mediante la oralidad y el aprendizaje no reglado, es considerada como una expresión menor, como subcultura dentro del acervo cultural colectivo.

Frente a esa infravaloración social del trabajo jornalero y de su cultura material, la historia de este sector social en los dos últimos siglos nos revela la continuidad de un discurso de autoidentificación como sujeto social inconformista, rebelde (a veces, "rebelde primitivo", según observa E. Hobswam 1983) y orgulloso de su oficio. Ese rechazo sostenido, a veces violento y siempre latente, del jornalero respecto al modelo de relaciones sociales de producción, que concentra el principal factor de producción (la tierra) en pocas manos y excluye de dicha apropiación a los jornaleros, está sustentado en la falta de legitimación de la propiedad de la tierra que no esté basada en el trabajo sobre ella. En la orientación cognitiva de los jornaleros la única apropiación legítima de la tierra es la que se alcanza por el trabajo ("la tierra para quien la trabaja") y la reversión de esa falta de legitimidad se logrará mediante la Reforma Agraria y el "reparto".

En definitiva, el trabajo en la tierra constituye el marcador con mayor capacidad de determinación de la identidad social del jornalero. Su cultura del trabajo, su identidad socio-profesional, obtiene sus raíces y alcanza su reproducción en los procesos de trabajo que, bajo determinadas relaciones sociales de producción, han venido realizando los jornaleros en el sector agrario, y su cosmovisión está también orientada por la percep- 
ción del trabajo como fuente de todo valor obtenido de la tierra y, en consecuencia, por la impugnación de toda forma de propiedad de la tierra que exceda a la que el titular cultive directamente.

\section{DEL TRABAJO AL SUBSIDIO: DISOLUCIÓN DE LA IDENTIDAD JORNALERA}

En el corto periodo de tiempo que representan tres décadas en la historia social de los jornaleros son claramente perceptibles los efectos combinados de dos medidas de naturaleza política que han afectado directamente a las condiciones de existencia del sector jornalero andaluz. Por un lado, la consolidación del proceso de modernización de la agricultura andaluza que ha transformado radicalmente los procesos de trabajo al sustituir en numerosas tareas la fuerza de trabajo que aportaban los jornaleros por máquinas y por insumos químicos. Por el otro, y directamente relacionado con el anterior proceso, la institucionalización de las prestaciones asistenciales en el campo andaluz que han alejado a los jornaleros del trabajo directo en la tierra para orientar su cotidianeidad hacia el objetivo de "vivir del paro".

La modernización de la agricultura andaluza se convierte, en el contexto del desarrollismo de los años sesenta, en un objetivo estratégico del gobierno franquista y de los sectores más avanzados de la oligarquía agraria que, una vez cerrada la etapa de la autarquía proteccionista que tantos beneficios les aportó, ven en la reordenación de cultivos y en su mecanización una nueva posibilidad de incremento de sus rentas agrarias. Al mismo tiempo, la nueva burguesía industrial y financiera está interesada en esta capitalización de la agricultura andaluza que supondrá un cambio de dirección de los excedentes financieros que la agricultura proporcionó a los demás sectores y que, a partir de ahora, absorberá de ellos, tal como demuestra Delgado Cabeza (1981).

Los efectos de dicho proceso sobre la reducción del empleo agrario, en un primer momento, se verán amortiguados por el éxodo migratorio desde el medio rural andaluz hacia los núcleos industriales del Estado español y de los países del centro europeo. Pero cuando ese flujo migratorio empieza a descender a finales de los sesenta, para cerrarse casi completamente a partir de 1973, las tensiones del desempleo creciente en el sector agrario andaluz se dejan sentir en el medio rural. Aunque, también es cierto que el contexto político del final del franquismo y el comienzo de la transición política funcionará como catalizador de dichas tensiones, incorporándolas a la corriente de reivindicaciones socio-políticas que caracterizaron esos años. 
Las primeras formas de resistencia jornalera en ese periodo estuvieron dirigidas hacia la defensa del trabajo en la tierra y contra la mecanización de los cultivos sin alternativas de empleo. Sin embargo, con las primeras formas de organización sindical jornalera que emergen después de un largo periodo de ostracismo (en 1966 se crean en Jerez las Comisiones Jornaleras), esa defensa del trabajo aparece articulada con la aspiración al reparto. Tierra y trabajo son pues los dos ejes de ese resurgir jornalero en la década de los sesenta.

La defensa del trabajo, aunque sea esporádico, mal retribuido y sometido al control discrecional de los patronos, se convierte en un objetivo perentorio ante el empuje de la mecanización de algunas tareas que, como la recogida del algodón o la siembra del arroz, proporcionaban una serie de jornadas de trabajo a todos los miembros del grupo doméstico. Además hay que tener en cuenta que la renta salarial era la única fuente de ingresos monetarios y que su desaparición no estaba cubierta por ningún tipo de prestaciones asistenciales de desempleo. El fantasma del hambre, aun no completamente desaparecido de la memoria de los jornaleros que sufrieron el fascismo agrario del primer fanquismo, volvía a hacerse presente en las casas de los obreros del campo. Pero, en esos momentos las condiciones de sometimiento y de represión no eran tan fuertes como al final de la Guerra Civil y la respuesta jornalera sale a la luz.

Alguna de las formas de esa protesta empiezan a recordar, peligrosamente para los terratenientes, las movilizaciones campesinas de la $2 .^{a}$ República: huelgas generales de ámbito municipal, ocupaciones de fincas, sabotajes de cosechas, quema de maquinaria, etc., con lo que la llamada "modernización de las estructuras agrarias" o la "vía prusiana de reforma agraria" que se estaba implantando en España podía ponerse en cuestión ante ese clima de tensión generalizada en el medio rural andaluz que desbordaba las medidas represivas de un régimen cada vez más acosado por la movilización democrática.

Por eso la nueva forma de intervención asistencialista del Estado en ese conflicto entre modernización agraria y reivindicaciones jornaleras va a cobrar, con el tiempo, una importancia tan trascendental. La puesta en marcha del Empleo Comunitario en 1971, como programa de asistencia pública a los municipios de Andalucía y Extremadura que tuvieran altos porcentajes de población jornalera y largos periodos de desempleo, se presenta como una medida política discrecional y de carácter coyuntural cuyos objetivos son paliar los efectos del desempleo agrario mediante la promoción de obras públicas en las que se emplee esa mano de obra agrícola que no encuentra trabajo en la tierra. En sus primeros años de vigencia el Empleo Comunitario recordó las prácticas asistenciales y cari- 
tativas que las autoridades civiles y religiosas adoptaban a favor de los jornaleros en épocas de sequía prolongada y grandes hambrunas.

El carácter discrecional de las ayudas y el hecho de que la decisión sobre el destino de los fondos recayera en los Gobernadores Civiles, previa aprobación de los proyectos de obras presentados por los Ayuntamientos, hizo del Empleo Comunitario una medida de orden público. Así, aquellos municipios con mayor capacidad de movilización jornalera fueron los principales beneficiarios de esas ayudas públicas en los primeros años. Pero el agravio comparativo hizo que los jornaleros de aquellos pueblos que no se habían distinguido por sus luchas sindicales comprendiesen que en este caso la movilización, aun con el riesgo de la represión, era rentable. De esta forma, la utilización del Empleo Comunitario como apagafuegos parecía que estaba dando los resultados contrarios al incentivar la movilización jornalera, incluso allí donde nunca tuvo existencia. Pero su eficacia real estaba en el hecho de haber desviado el punto de mira de dichas movilizaciones. Ahora las protestas se canalizaban hacia el Gobernador Civil y los Ayuntamientos y el objetivo central no era impedir la mecanización o defender el trabajo en la tierra, sino conseguir nuevos envíos de fondos para realizar obras que dieran trabajo durante unas semanas a los jornaleros. Trabajo que se ejecutaba en los núcleos urbanos, en el sector de la construcción, lejos de los ámbitos naturales en los que el jornalero ejerció su oficio.

La actividad sindical, más o menos organizada y siempre en condiciones de clandestinidad, se desvió hacia la conquista de la "limosna" del Empleo Comunitario y paulatinamente se fueron abandonando las reivindicaciones históricas. Ese auge sindical no dejó de ser un mero espejismo mantenido artificialmente dentro de una dinámica que llevó a algunos sindicatos a implicarse en la gestión directa de los fondos y en la selección de los beneficiarios (uno por cada unidad familiar jornalera). La colaboración sindical con una estrategia política que buscaba el alejamiento de los jornaleros de la tierra y el abandono de sus aspiraciones históricas se vio compensada con nuevas formas de clientelismo sindical y un mayor poder de incidencia en la política local.

La respuesta inmediata del gobierno franquista, y de los que le sucedieron a partir de la transición democrática hasta 1984, fue el mantenimiento del sistema y la ampliación constante de los presupuestos (de los 526 millones que se destinaron en 1971 al Empleo Comunitario se pasó a más de 25.000 millones en 1983) hasta alcanzar un grado de regularidad tal que el trabajo en el Empleo Comunitario se convirtió en uno de los componentes regulares, junto al salario y a los ingresos por actividades de economía sumergida, de la renta familiar jornalera. 
Desde los primeros años de vigencia del Empleo Comunitario se fueron diseñando dos posiciones en el seno del movimiento jornalero. La de aquellos que percibieron los efectos perversos que a medio y largo plazo tendría el alejamiento del jornalero del trabajo en la tierra y la pérdida de su identidad como trabajador agrícola y propusieron el rechazo de la "limosna del paro", aun reconociendo la importancia de ese ingreso monetario regular para las economías domésticas, y la de quienes intentaron justificar la recepción de esos fondos como pago de una supuesta deuda histórica de la sociedad para con los jornaleros, verdaderos artífices de la riqueza extraída de la tierra y tan poco favorecidos por ella. Esta posición oportunista sirvió de caución para generalizar, en los últimos años de vigencia del Empleo Comunitario, la distribución de las subvenciones sin que ello implicase la obligación de realizar trabajo alguno por parte de los jornaleros beneficiados.

La rentabilidad social, desde el punto de vista de los intereses de la modernización agraria, y la utilidad para la consolidación artificial de algunos sindicatos, además de la eficacia del Empleo Comunitario como instrumento de captación de fidelidades electorales en las primeras elecciones municipales democráticas de 1979, hicieron que ninguna fuerza política democrática se plantease la posibilidad de suspender ese programa asistencial, en principio coyuntural y cada vez más estructural, como veremos a continuación.

A finales de 1983, apenas un año después el triunfo electoral del PSOE en las elecciones generales de 1982, se realizó un estudio en profundidad de los objetivos alcanzados y también de las disfuncionalidades del Empleo Comunitario y se llegó a la conclusión de la necesidad de una reforma del sistema que avanzase en su institucionalización. A partir de enero de 1984 el Empleo Comunitario es sustituido por un sistema de prestaciones asistenciales que, sin llegar al modelo de prestaciones contributivas del Régimen General de la Seguridad Social, deja de ser discrecional para convertirse en el derecho de cada afiliado al Régimen Especial Agrario (REA) a percibir durante nueve meses un Subsidio de Desempleo Agrario, una vez cumplidas determinadas condiciones (estar al corriente del pago de la cuota mensual del REA y demostrar haber realizado al menos 60 jornadas de trabajo por cuenta ajena en el sector agrario o en las obras del Plan de Empleo Rural durante los doce meses anteriores a la percepción del Subsidio).

Respecto al Empleo Comunitario el nuevo Subsidio representa la garantía de la percepción una vez cumplidos los requisitos exigidos. Además se convierte en un derecho individual, con lo que es posible acumular varios subsidios en el seno de cada grupo familiar. Esta posibilidad 
dará lugar al incremento de la afiliación en el REA de las mujeres jornaleras y de los jóvenes, hasta entonces beneficiarios de la cartilla del cabeza de familia (en 1990 los beneficiarios del Subsidio eran 397.639, seis veces más que los del Empleo Comunitario en 1983) y, sobre todo, al incremento de los ingresos familiares por acumulación de varias prestaciones asistenciales. En nuestra investigación en Lebrija pudimos comprobar cómo ya en 1984 los ingresos del Subsidio y los salarios del PER habían superado en cuantía a las rentas salariales en las economías domésticas jornaleras.

Siendo muy considerable el incremento de ingresos por prestaciones asistenciales que supone el Subsidio y sin menospreciar la importancia de su garantía y regularidad, lo más significativo, en nuestra opinión, es el hecho de que a partir de enero de 1984 ya no son necesarias las movilizaciones colectivas para acceder a los beneficios del subsidio. La motivación utilitarista que llevaba a los jornaleros a participar en las convocatorias sindicales para percibir el Empleo Comunitario se transforma en un esfuerzo personal para "arreglar los papeles del paron. Con este nuevo sistema se consigue la "pacificación" casi total del campo andaluz y se desplaza al jornalero de su medio natural (la tierra) hacia un nuevo universo burocrático en el que debe aprender a moverse (Oficina del INEM, Cámara Agraria, entidades bancarias, Delegación de Empleo de los Ayuntamientos, etc.).

El Subsidio de Desempleo Agrario no sólo trastoca la cotidianeidad del jornalero sino que contribuye a distorsionar el mercado de trabajo agrícola y la arena política, local y autonómica. En ambos casos, el requisito de acumular al menos sesenta firmas demostrativas de haber realizado otras tantas jornadas de trabajo por cuenta ajena, otorga a los titulares de explotaciones agrarias (incluidos los alcaldes, como titulares de las fincas de propiedad municipal) la potestad de facilitar o dificultar el acceso a las prestaciones. De ello se deducirán prácticas de sobreexplotación del trabajo y de consentimiento de los trabajadores y también fórmulas de clientelismo político-electoral, debido a la laxitud en el control de la autenticidad de las firmas de jornadas agrícolas.

En anteriores trabajos sobre el tema (Palenzuela 1989 y 1991) hemos analizado con detalle el impacto positivo de las prestaciones asistenciales en las estrategias económicas domésticas de los jornaleros andaluces y los efectos perversos de dicha política en los esquemas reivindicativos de dicho sector social, pero en este momento, y enlazando con las reflexiones teóricas que encabezan este trabajo, nos interesa profundizar en las consecuencias que en el plano identitario ha tenido el efecto combinado de la política de intensificación de las relaciones de producción capitalista en 
la agricultura andaluza y la institucionalización de las prestaciones asistenciales para los trabajadores eventuales agrarios.

Un colectivo socio-profesional como el jornalero andaluz que obtenía su identidad como sujeto social a partir de su inserción en procesos de trabajo específicos que dominó con su saber hacer y que, desde las prácticas colectivas desarrolladas en un determinado modelo de relaciones laborales, acumuló y trasmitió unas experiencias grupales de resistencia y/o de consentimiento, ha visto cómo se han diluido las bases materiales e ideacionales sobre las que se edificó esa identidad social, determinada estructuralmente desde la imbricación de su cultura del trabajo con su identidad étnica y su adscripción al sistema de sexo-género.

El trabajo era la piedra angular de esa construcción identitaria, pero no sólo en cuanto trabajo social (actividad específicamente humana e incluso factor de hominización) (Engels 1876), sino también como locus de las relaciones de producción que determinan en qué medida se pueden combinar las fuerzas de trabajo (la mano de obra jornalera) con los medios de producción disponibles (la tierra y los procedimientos tecnológicos) para expresar a través de ellas el reparto del poder y el antagonismo de intereses, tanto en el plano social (polarización terrateniente/ jornalero), como, de forma cotidiana y directamente perceptible, en los procesos de trabajo (jerarquización y sistemas de control). Asimismo, el trabajo concreto (la peoná), realizado en cooperación (la cuadrilla o el grupo familiar), encierra una serie de operaciones y procedimientos (las faenas) que expresan tanto un modelo de organización técnica del trabajo (a jornal o a destajo) como el resultado de la experiencia en el manejo de los cultivos. Ese patrimonio de saberes y de experiencias colectivamente acumulado y transmitido a través de los procesos de trabajo conforma la base material de unas específicas culturas del trabajo que los jornaleros adquirieron a través de un recorrido temporal que los llevó desde el aprendizaje al dominio del "oficio de jornalero".

El mantenimiento de un conjunto de procedimientos técnicos y organizacionales en los procesos de trabajo induce de forma interactiva una serie de prácticas y de representaciones del trabajo relativamente estables que son compartidas por el colectivo de individuos que se insertan en dichos procesos de trabajo. P. Bouvier (1989: 21) propone el concepto de "bloque socio-tecnológico" para definir este conjunto de prácticas (formas de hacer) y de representaciones (formas de pensar) generadas desde el trabajo y expresadas en la cotidianeidad laboral y social a través de un catálogo de comportamientos, que adoptan formas ritualizadas debido a su carga simbólica y a su periodización dentro de una entidad relativamente estable y coherente, que son verbalizadas mediante un vo- 
cabulario específico y comunicadas por un código gestual y una estética colectiva.

Hasta la década de los sesenta, y con una relativa estabilidad durante más de un siglo de las relaciones de producción y de los modelos de organización del trabajo, los jornaleros andaluces, como sector social globalmente considerado, respondieron como un "bloque socio-tecnológicon compartiendo unas formas de hacer (los saberes del oficio), unas representaciones del trabajo ("el cumplir", la legitimidad de la propiedad de la tierra por el trabajo) y unas formas ritualizadas de impugnación de su rol social (huelgas, movilizaciones) o de consentimiento (servidumbre, clientelismo). Todo ello expresado de forma explícita o latente en el día a día de los procesos de trabajo y en la interacción social.

Esa cultura del trabajo de los jornaleros, categoría estructurante de su identidad social, junto a su función social como fuerza de trabajo imprescindible en una actividad productiva tan trascendente para Andalucía y la persistencia de sus aspiraciones históricas al "reparto", que hicieron del problema de la tierra un marcador de la identidad andaluza, como afirma I. Moreno (1984), constituyó el marco esencial de referencia para que un colectivo socio-profesional se reconociese y fuera reconocido como portador de una identidad singularizada.

Hoy día, salvo algunos enclaves concretos en los que el SOC sigue manteniendo viva la defensa de la identidad jornalera y la aspiración a dejar de ser campesinos sin tierra, la mayor parte de esos jornaleros que "tan gallardamente se batían con una extraordinaria contextura moral" (Díaz del Moral 1979) a principios de los años setenta, han engrosado las filas de los excluidos del actual modelo de acumulación y mantienen sus estrategias económicas de subsistencia sobre la base de la percepción de los subsidios.

Una identidad social, cimentada sobre una cultura del trabajo cristalizada desde una determinada posición en las relaciones sociales de producción y expresada en prácticas sociales que adquieren sentido en el seno de una cosmovisión específica, se diluye desde el momento en que desaparecen las bases de su reproducción. Es decir, cuando se interrumpe la inserción en unos procesos de trabajo que permitieron a los jornaleros alcanzar el status de sujeto social ("vivir del trabajo", o sea, tener una existencia social desde el trabajo) se pone en marcha un proceso de desidentificación que los convierte en mera categoría administrativa ("vivir del paro", o sea, subsistir con las prestaciones asistenciales).

Sin embargo, mientras parece confirmarse "la agonía final de la conciencia jornalera", pronosticada por Alfonso Ortí en 1984, emerge la situación, en primera instancia paradójica, de que la llamada "nueva agricultu- 
ra" (por cierto, una de las consecuencias de la modernización agraria) esté absorbiendo un contingente creciente de mano de obra inmigrante, eventual y poco cualificada, que se inserta en procesos de trabajo y en relaciones de producción, similares a los que realizaron y vivieron los jornaleros antes de la mecanización de los cultivos. La coexistencia en el seno de esos procesos de trabajo de mano de obra andaluza e inmigrante podría ser la génesis de una nueva cultura del trabajo jornalera en Andalucía. En este caso, contribuirá a su conformación el carácter pluriétnico del colectivo.

\section{BiBLIOGRAFÍA CITADA}

BOUVIER, PIERRE. 1989. Le travail au quotidien. Paris: PUF.

Delgado Cabeza, Manuel. 1981. Dependencia y marginación de la economía andaluza. Córdoba: Publicaciones del Monte de Piedad y Caja de Ahorros.

DÍAZ DEL MORAL, JUAN. 1979. Historia de las agitaciones campesinas andaluzas. Madrid: Alianza (5." edic.).

ENGELS, FEDERICO. 1876. El papel del trabajo en la transformación del mono en bombre. Moscú: Ed. Progreso.

GODELIER, MAURICE. 1990. Lo ideal y lo material. Madrid: Taurus.

HABERMANS, JÜRGEN. 1992. La reconstrucción del materialismo bistórico. Madrid: Taurus. HOBSBAWM, ERIC. 1983. Rebeldes primitivos. Barcelona: Ariel

ITURRA, RAÚl. 1993. "Letrados y campesinos. El método experimental en la Antropología Económican, en E. Sevilla Guzmán y M. González de Molina (eds.), Ecología, campesinado e bistoria. Madrid: La Piqueta.

LENIN, VlaDIMIR. [1919] 1972. "Dos tácticas de la socialdemocracia”. Obras Completas. Vol.VIII. Moscú: Editorial Progreso.

LUKACS, GEORG. [1923] 1985. Historia y conciencia de clase. Barcelona: Orbis.

ORTí, ALFONSO. 1984. "Crisis del modelo neocapitalista y reproducción del proletariado rural: Represión, resurrección y agonía final de la conciencia jornaleran, en E. Sevilla Guzmán (ed.), Sobre agricultores y campesinos. Estudios de Sociología Rural en España. Madrid: Servicio de Publicaciones del Ministerio de Agricultura.

Martínez Alier, Juan. 1968. La estabilidad del latifundismo. Paris: Ruedo Ibérico.

MARX, KARL [1859] 1970. "Prefacio", en Contribución a la crítica de la economía política. Madrid: Alberto Corazón Editor.

MORENO NAVARRO, ISIDORO. 1984. "Reforma Agraria e identidad andaluza. Implicaciones simbólicas del problema de la tierra en Andalucía". Nación Andaluza 2/3: 91-96.

- 1991. "Identidades y rituales. Estudio Introductorio", en J. Prats et al. (eds.), Antropología de los Pueblos de España: 600-636. Madrid: Taurus.

Palenzuela, Pablo. 1989. "Estrategias económicas de los jornaleros andaluces: Salario, subsidio y economía sumergida. Agricultura y Sociedad 50: 75-107.

- 1991. "El Estado no inocente: naturaleza perversa y eficiencia de la política asistencial en el medio rural andaluz. Revista de Estudios Regionales 31: 213-222.

- 1995. "Las culturas del trabajo: una aproximación antropológica". Sociología del Trabajo. Nueva Época. 24: 3-28. 
- 1996. Buscarse la vida. Economía jornalera en las marismas de Sevilla. Sevilla: Delegación de Cultura del Ayuntamiento de Sevilla.

Palenzuela, Pablo y Cristina Cruces. 1995. «Don et échange dans le travail et la fête. Mauss en Andalousie.. Anthropologie et Sociétés. 19 (1-2): 119-138.

PoulantZas, Nicos. 1972. Pouvoir politique et classes sociales. Paris: Maspero.

Sumpsi, José M."a y JUAN MANUel NAREDO. 1984. “Evolución y características de los modelos disciplinarios del trabajo agrícola en las zonas de gran propiedad. Agricultura y Sociedad 33: 45-86.

TALEGo VázQuEZ, FÉlIX. 1996. Entre el trabajo y los subsisdios del estado. Los jornaleros de Lebrija. Lebrija: Hermandad de los Santos.

- 1997. "Sobre el nombre y el quién de los jornaleros andaluces". Trabajo. Revista Andaluza de Relaciones Laborales 3: 29-51.

TerRay, Emmanuel, 1969. Le marxisme devant les sociétés primitives. Paris: Maspero. 